\title{
Evaluation of Non Febrile Seizure Disorder on Mri with Correlation with Seizure Type And EEG Records in Children.
}

\author{
${ }^{1}$ Dr. Sameer R. Verma ${ }^{2}$ Dr.VandanaSardana, \\ ${ }^{1}$ Professor, Department of Radiodiagnosis, Subharti Medical College, Meerut, UP-250005 \\ ${ }^{2}$ Assistant Professor, Department of Microbiology, Subharti Medical College, Meerut, UP- 250005
}

\begin{abstract}
Evaluation of non febrile seizure disorder on MRI with correlation with seizure type and EEG records in children.

Objectives: The aim of this retrospective study was to investigate the spectrum of abnormality on MRI, to correlate MRI findings with the seizure type and EEG findings wherever available in children presenting with non febrile seizure disorder.

Patients And Methods: A retrospective hospital based study was done of 271 children who underwent brain MRI for seizure disorder with exclusion of febrile conditions, recent trauma and metabolic conditions from the study. The MRI findings were interpreted independently and subsequently correlated with clinical history and EEG findings wherever available from patients' records.

Results: More than half of the patients (53\%) were in the age group of 11-15 years. Generalised seizures were the most common seizure pattern in all age groups. Out of the 271 children included in the study, 106(39\%) had abnormal cranial MRI scans. The most common abnormality detected on MRI was granulomatous lesion in 56 cases (33.3\%), followed by periventricular leukomalacia/hypoxic ischemic encephalopathy in 12 cases (7.1\%), focal gliotic and encephalomalacic changes in 9 cases (5.4\%), congenital/developmental anomalies including leukodystrohies in 8 cases( $4.8 \%)$, mesial temporal sclerosis in 5 cases $(3 \%)$, hydrocephalous in 4 cases $(2.4 \%)$, and demyelinating conditions in 3 cases( $2 \%)$, while tumors (2 cases), cerebral atrophy (2 cases), vascular malformations (2 cases),non traumatic intracranial bleed (2 cases)and cerebral venous thrombosis (1 case) comprised the rest of the causes. Children with unclassified and partial seizures had high rate of abnormality detection on MRI, while those with primary generalized seizures had relatively lower rate of abnormality detection on MRI. Interictalawake scalp EEG findings were available in 100(37\%) cases. There was moderate positive correlation between abnormality detection on EEG and MRI(Pearson correlation coefficient, $r=0.65$ ).

Conclusions: This study shows that CNS granulomatous pathology andhypoxic ischemic encephalopathy were the two most common abnormalities detected on MRI and primary generalized seizures were the most common presentation in children presenting with non febrile seizures.

Prior knowledge of seizure type and EEG records can be helpful factors in increasing diagnostic efficacy of MRI and avoiding unnecessary imaging.
\end{abstract}

\section{Introduction}

Non febrile seizures occur in children of all ages and pose a clinical challenge in terms of cause, management and prognosis.In a study done by Van Den Berg et al (1), non febrile seizures in young children were more likely to be associated with male gender, low birth weight and congenital abnormalities of CNS compared to febrile seizures. Childhood afebrile seizures have been found to be recurrent and more likely associated with abnormalities on neuroimaging in various studies.(2,3,4) An epileptic seizure is a paroxysmal alteration in neurologic function resulting from abnormal excess neuronal electrical activity. The pathophysiologic basis of seizures is loss of normal neuronal excitation and inhibition, resulting in a state of relative hyperexcitability.(5)Seizures are classified into either generalized orpartial, with partial seizures being further divided into those without loss of consciousness (simple) and those where consciousness is lost or impaired (complex). Epilepsy is a chronic condition characterised by recurrent seizures unprovoked by an acute systemic or neurologic insult, the term itself does not indicate a specific underlying pathology.(6) The American Academy of Neurology guidelines for the evaluation of the first nonfebrile seizure in a child recommend a routine EEG for all children and urgent neuroimaging for children with postictal focal neurologic deficits. Strong consideration is recommended for nonurgent neuroimaging in certain clinical circumstances, including cognitive or motor impairment of uncertain etiology, unexplained abnormalities on neurologic examination, abnormal EEGs not representing a benign syndrome, seizures of partial onset, or in children under the age of 1 year.(7)

The role of neuroimaging is to i) identification of pathology that require specific therapy and ii) assist formulation of syndrome based or aetiological diagnosis.(8) CT scan is used in emergency situations and also as a complement to MRI for example to identify calcified lesions. Being much more sensitive than computed 
tomography $(\mathrm{CT})$, magnetic resonance imaging (MRI) is the technique of choice to identify an underlying cause in symptomatic epilepsy. However the sensitivity and diagnostic accuracy of MRI is in part determined by the technique of scanning and the experience of the interpreting radiologist with hence clinical data is mandatory to direct a proper investigation. $(9,10)$ This study was undertaken to evaluate non febrile seizure disorder on MRI in children with correlation with clinical seizure type and EEG records wherever available.

\section{Materials And Methods}

This hospital based retrospective study was conducted in Department of Radiodiagnosis, of a tertiary care teaching hospital in Northern India, which included 271 children who underwent brain MRI for seizure disorder between June 2015 and May 2017 with exclusion of febrile conditions, recent trauma and metabolic conditions.

The MRI findings were interpreted independently and subsequently correlated with clinical history and interictal awake scalp EEG findings(available in 80 cases) from patients records. MRI was performed on 1.5T GE SignaHde MRI scanner with the acquisition of the following sequences routinely:Axial TI spin echo, Axial and Cor T2 fast spin echo, Axial T2Flair,Axial DWI SE-EPI ( $b=1000$, all directions), Axial Gradient echo,Oblique Cor T2FLAIR and Cor 3D T1 spoiled gradient sequences. Additional thin section Fiesta $\mathrm{C}$ in desired plane and post gadolinium $\mathrm{T} 1$ sequences in axial/cor/sag planes where done wherever required.

\section{Results}

More than half of the patients (53\%) were in the age group of 11-15 years. Generalised seizures were the most common seizure pattern in all age groups (Table 1$)$.

Table 1: Type of seizure as per age of children

\begin{tabular}{|l|l|l|l|l|}
\hline \multirow{2}{*}{ Age group } & Number of & Seizure Type & \multicolumn{4}{|l|}{} \\
\cline { 3 - 5 } & patients & Partial(\%) & Generalised(\%) & Unclassified(\%) \\
\hline 0-5 years & 60 & $11(18.3)$ & $34(56.7)$ & $15(25)$ \\
\hline$>$ 5 years -11 years & 67 & $18(26.9)$ & $44(65.7)$ & $5(7.4)$ \\
\hline$>$ 11years- 15 years & 144 & $40(27.8)$ & $97(67.3)$ & $7(4.9)$ \\
\hline Total & $\mathbf{2 7 1}$ & $\mathbf{6 9}(\mathbf{2 5 . 4})$ & $\mathbf{1 7 5}(\mathbf{6 4 . 6})$ & $\mathbf{2 7}(\mathbf{1 0})$ \\
\hline
\end{tabular}

Overall most common seizure type was generalized tonic-clonic (43.4\% cases), followed by generalized tonic or clonic $(14.3 \%)$, complex partial $(11.9 \%)$, simple partial $(11.3 \%)$, partial seizures with secondary generalization (7\%), atypical absence (4.8\%) with rest of the seizure types comprising less than $10 \%$ of the cases. Abnormality on MRI was noted in 106/271(39\%)patients. Overall the most common abnormality detected on MRI was granulomatous lesion in $56(52.8 \%)$ cases followed by hypoxic ischemic encephalopathy in $12(11.3 \%)$ cases, focal gliotic and encephalomalacic changes in $9(8.5 \%)$ cases, congenital/developmental anomalies including leukodystrohies in 8(7.5\%) cases, mesial temporal sclerosis in 5 (4.7\%)cases , hydrocephalous in 4(3.8\%) cases, and demyelinating conditions in 3(2.8\%) cases, while tumors (2 cases), cerebral atrophy (2 cases), vascular malformations ( 2 cases), non traumatic intracranial bleed ( 2 cases)and cerebral venous thrombosis ( 1 case) comprised the rest of the causes.

In children upto five years of age most common abnormality noted on MRI were hypoxic ischemic encephalopathy and congenital/developmental anomalies, while in children older than five years of age, granulomatous lesions were the predominant pathology. (Table 2)

Table 2: Age group wise spectrum of abnormality detected on MRI

\begin{tabular}{|l|l|l|l|l|}
\hline \multirow{2}{*}{ MRI Abnormality } & \multicolumn{2}{|c|}{ Number of cases } & Total \\
\cline { 2 - 5 } & $\mathbf{0 - 5}$ years & $\mathbf{> 5 - 1 1}$ years & $\mathbf{1 1}$-15 years & T \\
\hline Granuloma & 3 & 19 & 34 & 56 \\
\hline Hypoxic ischemic encephalopathy (HIE) & 6 & 4 & 2 & 9 \\
\hline Focal gliosis/encephalomalacia anomaly & 6 & 1 & 6 & 8 \\
\hline $\begin{array}{l}\text { Congenital/developmental } \\
\text { Inclleukodystrophy) }\end{array}$ & 0 & 0 & 1 & 5 \\
\hline Mesial temporal sclerosis & 1 & 2 & 5 & 4 \\
\hline Hydrocephalous & 0 & 1 & 1 & 2 \\
\hline Intracranial tumor (ICH, SSPE, PRES, Neuroglial cyst, & 1 & 4 & 5 & 10 \\
\hline $\begin{array}{l}\text { Misc. } \\
\text { Atrophy) }\end{array}$ & & & \\
\hline
\end{tabular}

In partial seizure 43/69(62.3\%) patients had abnormality on MRI, in case of generalised seizures 46/175 (26.3\%) patients had abnormality on MRI while in patients with other seizure types (unclassified) 17/27 (63\%) had abnormality on MRI. This difference was statistically significant ( $p$ value $=0.003$ ). ( Table 3 ) 
In this study, a correlation between EEG and MRI was made. MRI abnormality was seen in 106/271 (39\%) of patients and EEG abnormality was seen in 52/100 (52\%) of patients for which EEG records/reports were available. A total of $34(70.3 \%)$ patients with normal EEG had normal MRI, while 38 (73\%)patients with abnormal EEG had abnormal MR scans. There was moderate positive correlation between abnormality detection on EEG and MRI. (Pearson correlation coefficient $r=0.65$ ). According the seizure type EEG abnormality was highest $(67 \%)$ in case of partial seizures while it was lowest in case of generalised seizures (44.6\%). (Table 3 )

Table 3: Distribution of abnormality on MRI and EEG as per seizure type

\begin{tabular}{|l|l|l|l|}
\hline Seizure type & Number of cases & $\begin{array}{c}\text { Abnormality on MRI } \\
(\%)\end{array}$ & $\begin{array}{l}\text { Abnormal EEG/EEG records } \\
\text { available }(\%)\end{array}$ \\
\hline Partial & 69 & $43(62.3 \%)$ & $20 / 30(67 \%)$ \\
\hline Generalised & 175 & $46(26.3 \%)$ & $29 / 65(44.6 \%)$ \\
\hline Others/unclassified & 27 & $17(63 \%)$ & $3 / 5(60 \%)$ \\
\hline
\end{tabular}

\section{Discussion}

In this study most of the patients were in the 11-15 years age group (53\%) and generalised seizures were most common seizure type $(64.6 \%)$ in the study group. These observations are in agreement with the studies by various authors who have found 10-30 years as the most common age group(11-15) and the range of patients with generalised seizures between 50-69\%, while 31-50\% had partial seizures.(14,16-18,22). However Chan et al (19) and Doescher et al (2) have found focal seizures more common than generalized seizures in children.

Two most common abnormalities detected on MRI were granulomatous lesion in 56(33.3\%) cases and hypoxic ischemic encephalopathy in 12 (7.1\%) cases.Likewise CNS infections/infestations, previous insult, and perinatal insult have been found to be most common etiologies associated with seizures in studies done by Mac et al (Asia)(20), Sebit et al (Africa)(21) and Senanayake et al.(22)Children with unclassified and partial seizures had higher rate of abnormality detection on MRI compared to those presenting with primary generalized. This difference was statistically significant ( $\mathrm{p}$ value $=0.003$ ). Studies done by Rasool et al $(23)$, Bachman et al $(24)$ and Resta et al(25) have also found higher frequency of abnormal neuroimaging with partial seizures.In our study according the seizure type EEG abnormality was highest (67\%) in case of partial seizures while it was lowest in case of generalised seizures (44.6\%).This is in partial agreement with study by Rasool et al (23) who found high rate of EEG abnormality in case of both partial and generalised seizures (approx.70\%).There was moderate positive correlation between abnormality detection on EEG and MRI. (Pearson correlation coefficient $\mathrm{r}=0.65$ ). Statistically significant correlation between abnormal EEG and abnormality detection on MRI has been found in studies done by Rasool et al(India)(22), Doescher et al(US)(2), Berg et al(US)(26), and by us in our previous study(15).

\section{Conclusion}

This study shows that CNS granulomatous pathology andhypoxic ischemic encephalopathy were the two most common abnormalities detected on MRI and primary generalized seizures were the most common presentation in children presenting with non febrile seizures. Prior knowledge of seizure type and EEG records can be helpful factors in increasing diagnostic efficacy of MRI and avoiding unnecessary imaging.

\section{References}

[1]. Van der Berg BJ, Yerushalmy J.Studies on convulsive disorders in young children. I. Incidence of febrile and nonfebrile convulsions by age and other factors.Pediatr. Res.1969;3:298-304.

[2]. Doescher JS, deGrauw TJ, Musick BS, Dunn DW, Kalnin AJ, Egelhoff JC, et al. Magnetic resonance imaging and electroencephalographic findings in a cohort of normal children with newly diagnosed seizures. J Child Neurol 2006;21:491- 5.

[3]. Hsieh DT, Chang T, Tsuchida TN, Vezina LG, Vanderver A, Siedel J, et al. New onset afebrile seizures in infants.Role of neuroimaging. Neurology 2010;74(2):150-6.

[4]. Shinnar S, O'Dell C, Mitnick R, Berg AT, Moshe SL. Neuroimaging abnormalities in children with an apparent first unprovoked seizure.Epilepsy Res. 2001;43(3):261-9.

[5]. 5Gupta V, Ronen RA. In: Atlas SW. ed Magnetic resonance imaging in brain and spine. 4th edition. Philadelphia. Lipincott Williams \& Wilkins;2009.

[6]. FauciSA,KasperDL,LongoDL, Braunwald E, Hauser SL,Jameson JL et al editors.In Harrison's principles of internal medicine. 17th edition, Newyork:McGraw Hill;2008.Chapter 363,Seizures and epilepsy.

[7]. Hirtz D, Ashwal S, Berg A, Bettis D, Camfield C, Camfield P, et al. Practice parameter:evaluating a first nonfebrile seizure in children: report of the quality standards subcommittee of the American Academy of Neurology, the Child Neurology Society and the American Epilepsy Society. Neurology 2000;55:616 -23.

[8]. Recommendations for neuroimaging of patients with epilepsy. Commission on Neuroimaging of the International League Against Epilepsy.Epilepsia. 1997;38:1255-6.

[9]. Guissard G, Damry N, Dan B, David P, Sékhara T, Ziereisen F, Christophe C. [Imaging in paediatric epilepsy].Arch Pediatr. 2005;12(3):337-46. [article in French]

[10]. Bradley WG, Shey RB. MR imaging evaluation of seizures. Radiology 2000;214:651-6. 
[11]. Huang M, Hong Z, Zeng J, Rong X, Sheng Y, Lu C.[The prevalence of epilepsy in rural Jinshan in Shanghai]. Zhonghua Liu Xing Bing XueZaZhi 2002;23: 345-46. [article in Chinese]

[12]. Li SC, Schoenberg BS, Wang CC, Cheng XM, Zhou SS, Bolis CL. Epidemiology of epilepsy in urban areas of the People's Republic of China. Epilepsia 1985;26:391-94.

[13]. Fong GC, Mak W, Cheng TS, Chan KH, Fong JK, Ho SL.A prevalence study of epilepsy in Hong Kong. Hong Kong Med J. 2003;9:252-57.

[14]. Tran DS, Odermatt P, Le TO, Huc P, Druet-Cabanac M, Barennes H, et al. Prevalence of epilepsy in a rural district of central Lao PDR. Neuroepidemiology.2006;26:199-206.

[15]. Verma SR, Sardana V, Gupta PK, Verma SC, Munshi A, Suryavanshi A. Evaluation Of Non Febrile Seizure Disorder On MRI With Correlation With Seizure Type And EEG Records In A Tertiary Care Teaching Hospital. The Internet Journal of Third World Medicine[Internet]. 2013;11:1.

[16]. Radhakrishnan K, Pandian JD, Santhoshkumar T, Thomas SV, Deetha TD, Sarma PS, et al. Prevalence, knowledge, attitude and practice of epilepsy in Kerala, South India. Epilepsia 2000;41:1027-35.

[17]. Loh NK, Lee WL, Yew WW, Tjia TL. Refractory seizures in a young army cohort. Ann Acad Med Singap. 1997;26:471-74.

[18]. Kwong KL, Chak WK, Wong SN, et al. Epidemiology of childhood epilepsy in a cohort of 309 Chinese children. PediatrNeurol 2001;24: 276-82.

[19]. Chan D1, Phuah HK, Ng YL, Choong CT, Lim KW, Goh WH.Pediatric epilepsy and first afebrile seizure in Singapore: epidemiology and investigation yield at presentation.J Child Neurol. 2010;25(10):1216-22.

[20]. Mac TL, Tran DS, Quet F, Odermatt P, Preux PM, Tin-Tan C. Epidemiology, aetiology, and clinical management of epilepsy in Asia: a systematic review. Lancet Neurol 2007;6:533-43.

[21]. Sebit MB, Mielke J. Epilepsy in sub-Saharan Africa: its socio-demography, aetiology, diagnosis and EEG characteristics in Harare, Zimbabwe. East Afr Med J. 2005:82(3):128-37.

[22]. Senanayake N, Roman GC. Epidemiology of epilepsy in developing countries. Bulletin of the World Health Organization.1993;71(2):247-258.

[23]. Rasool A, Choh SA, Wani NA, Ahmad SM, Iqbal Q. Role of electroencephalogram and neuroimaging in first onset afebrile and complex febrile seizures in children from Kashmir. J PediatrNeurosci 2012;7:9-15.

[24]. Bachman D, Hodges PI, Freeman JM. Computed axial tomography in chronic seizure disorder of childhood. Paediatrics 1976;58:356-67.

[25]. Resta M, Palma M, Dicuonzo F, et al. Imaging studies in partial epilepsy in children and adolescents. Epilepsia 1994;35:11871193 .

[26]. Berg AT, Testa FM, Levy SR, Shinnar S. Neuroimaging in children with newly diagnosed epilepsy: a community based study. Pediatrics 2000;106:527-532. 